Volume 5

Issue 2 Reducing Discrimination in the

Workplace

2019

\title{
Special Issue on Reducing Discrimination in the Workplace: An Introduction
}

\author{
Mikki Hebl \\ Rice University \\ Juan M. Madera \\ University of Houston \\ Whitney Botsford Morgan \\ University of Houston-Downtown
}

Follow this and additional works at: https://scholarworks.bgsu.edu/pad

Part of the Human Resources Management Commons, Industrial and Organizational Psychology

Commons, and the Other Psychology Commons

How does access to this work benefit you? Let us know!

\section{Recommended Citation}

Hebl, Mikki; Madera, Juan M.; and Botsford Morgan, Whitney (2019) "Special Issue on Reducing

Discrimination in the Workplace: An Introduction," Personnel Assessment and Decisions: Number 5 : Iss. 2 , Article 1.

DOI: https://doi.org/10.25035/pad.2019.02.001

Available at: https://scholarworks.bgsu.edu/pad/vol5/iss2/1

This Editorial is brought to you for free and open access by the Journals at ScholarWorks@BGSU. It has been accepted for inclusion in Personnel Assessment and Decisions by an authorized editor of ScholarWorks@BGSU. 


\title{
Special Issue on Reducing Discrimination in THE WORKPLACE: AN INTRODUCTION
}

\author{
Mikki Hebl', Juan Madera'2 , and Whitney Botsford Morgan ${ }^{3}$
}

\author{
1. Rice University \\ 2. Conrad N. Hilton College of Hotel and Restaurant Management, University of Houston \\ 3. University of Houston-Downtown
}

Two years ago, after becoming one of the associate editors for Personnel Assessment and Decisions (PAD), Mikki pitched an idea to the Editor, Scott Highhouse, that we should consider publishing a Special Issue focusing on topics related to Diversity and Inclusion. Not surprisingly, Scott was encouraging and gave her the latitude to choose co-editors and define the issue as she saw fit. Thereafter, Mikki invited two co-editors, both of whom are associate professors who also happen to work in the Houston area. These two individuals, who have worked hard to make this issue what it is, are Juan Madera, Associate Professor at the Conrad N. Hilton College of Hotel and Restaurant Management, University of Houston, and Whitney Botsford Morgan, Associate Professor at the Marilyn Davies College of Business, University of Houston-Downtown. Like Mikki, Juan's research focuses on issues related to diversity and discrimination in the workplace, and he also examines more general employment interview and selection-related issues. Whitney's research focuses on the emergence and reduction of bias toward diverse individuals and issues related to the effective management of work-family conflict.

After getting the green light from Scott, the three of us met to determine the specific focus within D\&I work that we wanted the Special Issue to have, and we brainstormed ideas as to how our issue could have the greatest impact. One topic each of us has consistently researched and that continues to draw a need for public attention is the preponderance and continuation of workplace discrimination.

Despite the fact that the U.S. is now more than 50 years post-Civil Rights Act of 1964, discrimination against these protected and other unprotected groups remains. There are too many examples to draw upon but we cite just three. First, the recent \#MeToo Movement uncovered the rampant number of (mostly) women who are targets of sexual misconduct in the workplace and beyond. Although the problem has been identified clearly, many argue that far too little attention has been paid to making protective orga- nizational and legal changes to reduce the harassment. For instance, in the last two years, Congress has passed no laws to help better protect targets.

Second, there are 28.2 million immigrants in the U.S. labor force, which constitutes $17.4 \%$ of the total workforce (Bureau of Labor Statistics, 2018). And yet, a significant portion of this sizable workforce population - most recently, those from Mexico, other South American and Asian countries, and from what President Donald Trump disturbingly called "shithole countries" - face not only stereotypes and discrimination in the workplace but also dangerous rhetoric and exclusionary policies from our executive branch of government (see Bradley-Geist \& Schmidtke, 2017). Studies from other countries show the same exclusionary trends, and they are happening in both the public and private sectors (e.g., Van Ramshorst, 2018; Villadsen \& Wulff, 2018).

Third, the Christian-centric sentiment in the U.S. and many Western countries that results in workplace discrimination against religious minorities, particularly Muslims, is also far reaching. A recent meta-analysis (initially intended to be part of this series) that was published last year examined 46 independent effect sizes from 26 different sources and multiple countries, and they found that Muslim and Arab employees faced discriminatory judgments, behaviors, and decisions (Bartkoski, Lynch, Witt, \& Rudolph, 2018).

Given the continued discrimination that these and so many other groups (e.g., other racial/ethnic minorities, individuals with physical and/or cognitive disabilities, LGBT, pregnant women) experience in the workplace, we decided that our Special Issue would center on uncovering effective ways to reduce discrimination in the workplace. More specifically, we invited authors to submit papers that addressed how the reduction of discrimination is related to staffing organizations, applicant recruitment and assessment, selection tools and decisions, training, job search 
and choice, performance assessment, and job analysis. We further specified that the papers might address the reduction of workplace discrimination via diversity training, diversity management, particularly effective selection methods, organizational policies and initiatives, and target strategies.

After the standard PAD peer review process, 11 papers were accepted for this Special Issue. All of these articles deal with some aspect of remediating discrimination, and we begin by first presenting those that focus on strategies that individuals - whether targets, themselves, or allies can adopt to remediate the workplace discrimination they experience or witness. This includes the work by Ruggs et al., who examine the relative efficacy of racial acknowledgments in a variety of contexts. The results reveal that racial acknowledgments have benefits for targets (e.g., increased self-esteem) and in some instances are perceived favorably by receivers. The work by Madera and Hebl also focuses on the acknowledgment strategy. Specifically, they examine how a facial stigma affects visual attention during a technology-mediated interview and how applicants might reduce the amount of visual attention on a facial stigma by directly acknowledging their stigma. They find that facial stigmas draw visual attention during a computer-mediated interview, which decreases over time. However, the trajectory of the decrease in visual attention depended on whether an applicant acknowledged their stigma during the interview such that the decrease in visual attention was faster in the acknowledgment condition than in the control condition. This research provides a better understanding as to how a facial stigma influences the interview process and provides a theoretical rationale for why acknowledging a facial stigma benefits the interview process.

The work of Holmes et al. looks at target strategies that those managing an LGBT identity in the workplace can adopt. Their review shows that there are several effective compensatory identity management strategies that individuals can use to mitigate the bias and discrimination that they might experience due to their social identity. Specifically, they review the research on humor, avoidance, affiliation, enhancement, and social category label switching strategies, outline the identities with which these strategies could be used, and highlight strengths and weaknesses of each of the strategies. The work of Singletary Walker and Botsford Morgan examines the strategies that pregnant job applicants can utilize when applying for professional jobs. Their results show that pregnant women can increase the amount of positivity that they experience when providing counter-stereotypical information related to the stereotypes associated with pregnancy. Specifically, they found that providing information about one's competence results in more positive interactions for pregnant job applicants who are seeking professional positions. And finally, the work of Cheng et al. broadens the scope of individual-level foci by examining not the target's potential behaviors but those of the ally. Focusing on allies is a critical, yet understudied discrimination reduction strategy. In their research, they explore women's views of their male allies' behavior using an inductive critical incident approach. This approach asks women to report what is and is not effective, with the hope that this, in turn, can direct male allies on identifying the biases they possess but of which they were previously unaware. Additionally, it can direct them to behave in educated ways that are deemed most supportive and nondiscriminatory toward their female colleagues.

The second set of papers moves beyond the individual-level approach and focuses on remediating discrimination at the organizational level. These studies draw researchers' and HR practitioners' attention to strategic workplace behaviors and programs that they can institute to help reduce discrimination. To begin, the work by Mendoza et al. examines whether "if-then" plans, known as implementation intentions, can be used to reduce bias against women (compared to men) in work performance evaluations. The results show that implementation intention strategies focused on triggering perspective-taking led to more positive evaluation of the applicant (regardless of their gender) and less hostile sexism, which is an important set of findings that HR professionals can easily implement to reduce workplace bias. Boykin and Smith's work looks at the roles of both Internal and External Motivations to Control Prejudice (IMS \& EMS) in White mentor's ratings of their underrepresented minority mentees performance in a speech task. Results demonstrate that while independent coder ratings of mentee performance correlate with mentor's ratings of their mentees, mentors ratings were also uniquely predicted by both IMS and EMS. Making mentors aware of their biases, then, may be key to also reducing workplace discrimination. The paper by Jones et al. focuses on how the framing of an organization's affirmative action program impacts the relationships between group-image threat, affirmative action policy attitudes, and trust that non-beneficiaries have towards that organization. Their results show that relationships between group-image threat and both policy attitudes and trust were stronger for the diversity value framing and weaker for the past discrimination framing. Finally, Lindsey et al.'s paper focuses on discrimination reduction and specifically examines a new diversity training activity they call "reflection." Results from an online experiment with two time points and many training participants support their theoretical model by showing that, relative to other training interventions (perspective taking and goal setting) and a control condition, reflection was most effective at promoting internal motivation to respond without prejudice, which in turn produced beneficial effects on diversity-related attitudes and behaviors. Their results further revealed that this indirect effect was moderated by trainee social dominance 
orientation, such that reflection was more effective for individuals high on this trait, indicating that reflection may be an effective way to reach resistant trainees.

The third set of studies focus on broader strategies to reduce discrimination. To begin, the paper by Baldridge et al. examines the barriers to equal employment opportunities that persons with disabilities experience. Education has been identified as an important equalizer, yet the extent to which educational attainment impacts career outcomes for persons with disabilities is complex and not currently fully understood. Examining the American Community Survey 2015 , which includes 40,438 persons with disabilities, they find that while persons with disabilities as a whole benefit from greater educational attainment, they are also less successful in converting educational gains into earning gains. Baldridge considers the importance of harnessing diverse talent in organizations and outlines suggestions for HR practitioners who seek effective ways to reduce workplace discrimination against those who have disabilities. Finally, the research by Fa-Kaji et al. examines what happens when institutions use racially-biased public service announcements that are intended to protect but actually show harm toward groups of individuals. In particular, their research examines how the inclusion of suspect race in crime reports can lead to greater bias and discrimination against Black individuals. They find that participants who read crime reports in which the suspect's race is given as Black later demonstrate greater negative bias against Blacks and other historically marginalized groups. In contrast, participants who read crime reports in which the suspect's race is omitted do not demonstrate such bias. They discuss the implications of removing the bias from institutions that maintain inequities, stereotypes, and discrimination.

We are delighted with the 11 papers that we helped usher into this Special Issue and hope that you enjoy them as much as we did. Moreover, we hope that you will be inspired to take action - whether it is at the individual-lev$\mathrm{el}$, as an ally, at the organizational-level, or policy based. Whether you are a researcher, a practitioner, or just a reader of PAD, there is a role for you to play in reducing workplace discrimination. With everyone aboard, all things are possible, and we think that includes a workplace without discrimination.

\section{REFERENCES}

Bartkoski, T., Lynch, E., Witt, C., \& Rudolph, C. (2018). A meta-analysis of hiring discrimination against Muslims and Arabs. Personnel Assessment and Decisions, 4(2), 1-16. doi:10.25035/ pad.2018.02.001

Bradley-Geist, J. C., \& Schmidtke, J. M. (2017). Immigrants in the workplace: Stereotyping and discrimination. A.J. Colella, E.B. King (Eds.), The Oxford handbook of workplace discrimination, Oxford University Press, New York, NY (2018), pp. 159175.

Jameel, M. (June, 2019). More and more workplace discrimination cases are being closed before they're even investigated: It's a problem that starts with Congress. Vox. Retrieved from https://www.vox.com/identities/2019/6/14/18663296/ congress-eeoc-workplace-discrimination

Bureau of Labor Statistics (2018). Foreign-born workers: Labor force characteristics 2018. Released May 16, 2019. Retrieved from https://www.bls.gov/news.release/pdf/forbrn.pdf

Van Ramshorst, J. P. (2018). Anti-immigrant sentiment, rising populism, and the Oaxacan Trump. Journal of Latin American Geography, 17(1), 253-256.

Villadsen, A. R., \& Wulff, J. N. (2018). Is the public sector a fairer employer? Ethnic employment discrimination in the public and private sectors. Academy of Management Discoveries, 4(4), 429-448. 